Prepared for the U.S. Department of Energy

under Contract DE-AC05-76RL01830

\title{
Source Recertification, Refurbishment, and Transfer Logistics
}

\section{ZN Gastelum \\ LL Duckworth \\ BA Greenfield \\ SR Doll}

September 2013

Pacific Northwest

NATIONAL LABORATORY

Proudly Operated by Battelle Since 1965 

PNNL-22810

\title{
DISCLAIMER
}

This report was prepared as an account of work sponsored by an agency of the United States Government. Neither the United States Government nor any agency thereof, nor Battelle Memorial Institute, nor any of their employees, makes any warranty, express or implied, or assumes any legal liability or responsibility for the accuracy, completeness, or usefulness of any information, apparatus, product, or process disclosed, or represents that its use would not infringe privately owned rights. Reference herein to any specific commercial product, process, or service by trade name, trademark, manufacturer, or otherwise does not necessarily constitute or imply its endorsement, recommendation, or favoring by the United States Government or any agency thereof, or Battelle Memorial Institute. The views and opinions of authors expressed herein do not necessarily state or reflect those of the United States Government or any agency thereof.

\author{
PACIFIC NORTHWEST NATIONAL LABORATORY \\ operated by \\ BATTELLE \\ for the \\ UNITED STATES DEPARTMENT OF ENERGY \\ under Contract DE-AC05-76RL01830
}

Printed in the United States of America
Available to DOE and DOE contractors from the Office of Scientific and Technical Information,
P.O. Box 62, Oak Ridge, TN 37831-0062;
ph: (865) 576-8401
fax: $(865) 576-5728$
email: reports@adonis.osti.gov

\author{
Available to the public from the National Technical Information Service \\ 5301 Shawnee Rd., Alexandria, VA 22312 \\ ph: (800) 553-NTIS (6847) \\ email: orders@ntis.gov <http://www.ntis.gov/about/form.aspx> \\ Online ordering: http://www.ntis.gov
}

This document was printed on recycled paper.

(8/2010) 


\section{Source Recertification, Refurbishment, and Transfer Logistics}

ZN Gastelum

LL Duckworth

BA Greenfield

SR Doll

September 2013

Prepared for

the U.S. Department of Energy

under Contract DE-AC05-76RL01830

Pacific Northwest National Laboratory

Richland, Washington 99352 


\section{Contents}

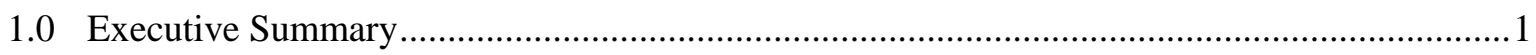

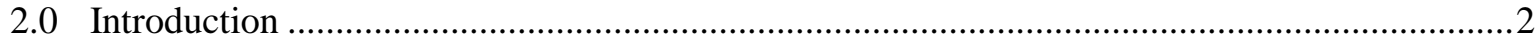

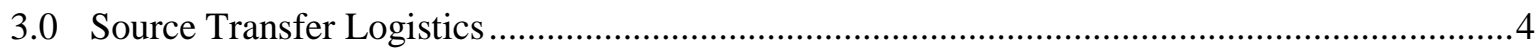

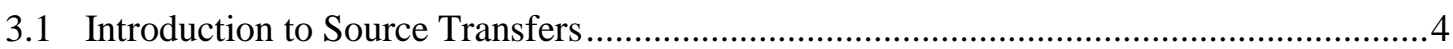

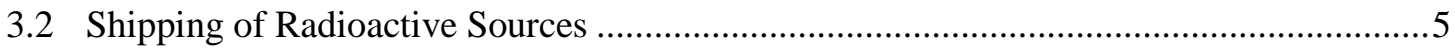

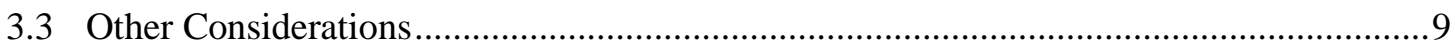

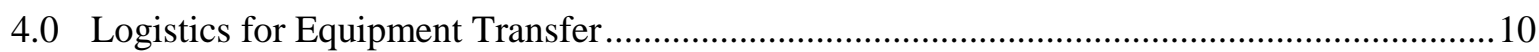

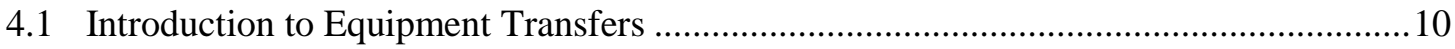

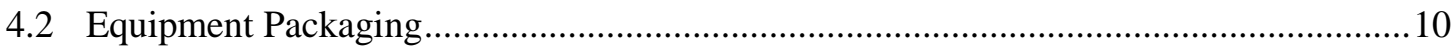

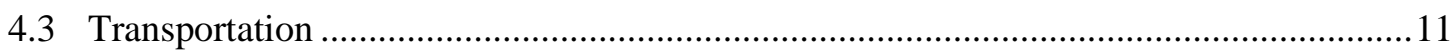

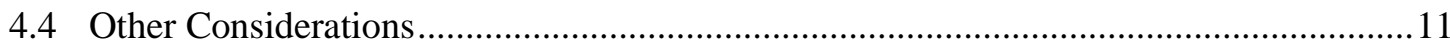

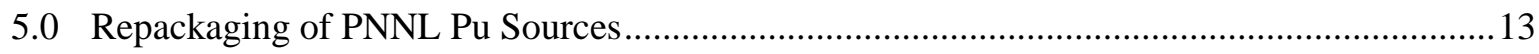

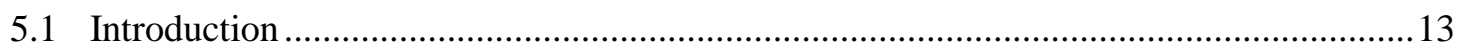

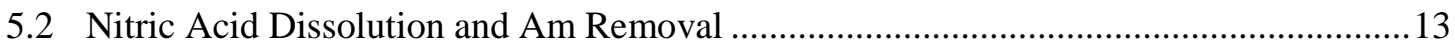

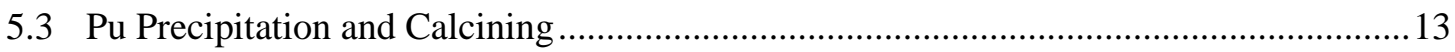

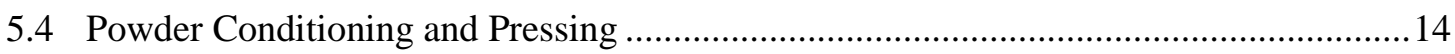

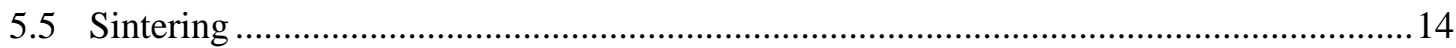

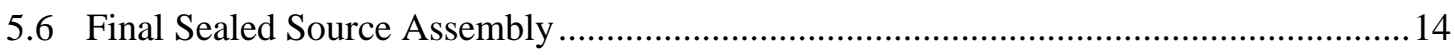

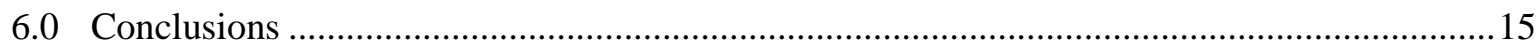

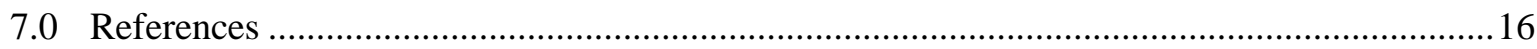




\section{Acronyms}

\begin{tabular}{ll} 
CFR & Code of Federal Regulations \\
DNC & Certificate of Compliance \\
DOE & Domestic Nuclear Detection Office \\
DOT & Department of Transportation \\
FMH & Fissile Material Handler \\
LOE & Level of Effort \\
MBA & Material Balance Area \\
NRC & Nuclear Regulatory Commission \\
PNNL & Pacific Northwest National Laboratory \\
POC & Point of Contact \\
RPL & Radiochemical Processing Laboratory \\
& \\
\hline RID & Tamper-Indicating Device \\
\hline Pation Protection Technical
\end{tabular}


PNNL-22810

\subsection{Executive Summary}

The 2012 Gap Analysis of Department of Energy Radiological Sealed Sources, Standards, and Materials for Safeguards Technology Development [1] report, and the subsequent Reconciliation of Source Needs and Surpluses across the U.S. Department of Energy National Laboratory Complex [2] report, resulted in the identification of 33 requests for nuclear or radiological sealed sources for which there was potentially available, suitable material from within the U.S. Department of Energy (DOE) complex to fill the source need. Available, suitable material was defined by DOE laboratories as material slated for excess, or that required recertification or refurbishment before being used for safeguards technology development. This report begins by outlining the logistical considerations required for the shipment of nuclear and radiological materials between DOE laboratories. Then, because of the limited need for transfer of matching sources, the report also offers considerations for an alternative approach the shipment of safeguards equipment between DOE laboratories or technology testing centers. Finally, this report addresses repackaging needs for the two source requests for which there was available, suitable material within the DOE complex. 
PNNL-22810

\subsection{Introduction}

In fiscal year (FY) 2012, Pacific Northwest National Laboratory (PNNL) conducted a survey of U.S. Department of Energy complex sites to catalogue their source needs for safeguards technology development and calibration. In addition to source requests, the survey also collected information on sources that were being excessed which could potentially be used for safeguards technology development, or material that required refurbishment or recertification prior to its safeguards use. Results of that survey were reported in the Gap Analysis of Department of Energy Radiological Sealed Sources, Standards, and Materials for Safeguards Technology Development [1]. As a result of questions that remained after the first Gap Analysis iteration, the original results were revisited and validated in the 2013 Reconciliation of Source Needs and Surpluses across the U.S. Department of Energy National Laboratory Complex [2] report, hereafter referred to as the Reconciled Gap Analysis report.

The results of the Reconciled Gap Analysis report indicated 33 potential source requests and availability matches within the complex. Although the potential matches appeared to be consistent with the initial request, detailed need parameters introduced the necessity for requestor validation of the proposed source suitability before transfer of sources between sites could be arranged. The outcome of this requestor validation effort is described in Final Results of the DOE Complex Radiological/Nuclear Source Suitability Questionnaire [3], hereafter called the Source Suitability report. The Source Suitability report resulted in the confirmation of only two source requests that could be filled from existing DOE materials. These source requests and available material, however, were from the same laboratory, and in fact from a single Point of Contact (POC) who needed his existing material to be repackaged for use in safeguards technology development. As a result of this circumstance, no inter-laboratory transfer would be necessary. While the Source Suitability report was not able to identify sources within the DOE complex that could meet the needs of the majority of requestors, similarities in requests for a number of different source types, could be met by a strategic DOE source procurement and laboratory sharing program. While the original intent of this report was to describe the specific logistics required for transfers resulting from source requests and availability matching within the DOE complex, it would still be applicable to the potential DOE procurement and transfer of sources between laboratories. These considerations are described in Section 3.0 of this report.

Because the majority of the source requests identified in the Reconciled Gap Analysis report cannot be met through within-complex transfers, procurement of those sources will be necessary to fulfill the remaining source requests. The requested sources may be available through commercial or government vendors (described in Final report on the Commercial and Government Vendor Availability of Requested Sources without In-Complex Available Matches [4]) or from custom orders to DOE national laboratories, universities, industry, or other vendors. Due to the similarity between many of the remaining source requests, it may be less costly to house a collection of sources at regionally accessible testing centers, rather than buying multiple, similar sources for broader distribution. In such a case, DOE researchers could ship their safeguards equipment to the testing centers, rather than shipping materials to the equipment, alleviating the complex problems associated with material transfers, controls and accountancy. Considerations for shipping equipment between DOE sites are described in Section 4.0 of this report. 
Due to the prospect of fulfilling two source requests by repackaging existing materials at PNNL, the report offers a brief summary of the source repackaging process and expected costs in Section 5.0. Finally, conclusions are presented in Section 6.0. 
PNNL-22810

\subsection{Source Transfer Logistics}

This section summarizes the requirements for various radioactive material shipments throughout the DOE complex and identifies the major obstacles and risks of performing such shipments. Most shipments of radioactive material between DOE sites require substantial effort and planning to accomplish.

Accordingly, the shipping of radioactive material may result in significant costs. The associated costs can vary widely depending upon a number of factors, including whether or not the appropriate shipping container is available, who owns and holds responsibility over that container and their willingness to use it if the container doesn't belong to the receiver, and the training and availability of appropriate staff. Container issues aside, some of the largest costs are centered on staffing level of effort (LOE) and the logistics of identifying the exact staff both at the origin and destination of the shipment. Successful shipments require a well thought out plan with a team of professionals willing to coordinate and communicate effectively, and sufficient lead time to correctly complete the transaction.

\subsection{Introduction to Source Transfers}

Radioactive material as defined in 49 CFR 173.403 is any material containing radionuclides, where both the activity concentration and the total activity in the consignment exceed the values specified in the tables in 49 CFR 173.436 or values derived according to instructions in 49 Code of Federal Regulations (CFR) 173.433. ${ }^{1}$ The U.S. Department of Transportation (DOT) and the U.S. Nuclear Regulatory Commission (NRC) have established mass thresholds specific to individual radioactive isotopes above which the material becomes "accountable," and must be treated adherent to guidelines laid out in DOT CFR 49 and 10 CFR 71.

The specific transportation and packaging requirements for radioactive material shipments are addressed in DOT CFR 49. The higher the dose rate and more "attractive" the material being shipped, the more restrictions and requirements are placed on the shipment. Material attractiveness refers to a radioactive material's perceived usefulness for weapons of mass destruction/effect. The physical form of a radioactive source also drives how the material is allowed to be shipped. Form refers to the physical configuration of the radioactive material; whether it's in a robust package or in arrangement more fragile container.

While there are a number of similarities in radioactive materials shipment requirements, each shipment of radioactive material is unique. The combination of requirements placed on the shipper and receiver is specific to the isotope, quantity, dose rate, and material attractiveness, as well as including specific requirements associated with the sites, locations and Material Balance Areas (MBAs) associated with the material shipment. Shipping is further complicated by the fact that radioactive sources are not allowed to be shipped by air. Ground transportation is currently the only option for transporting radioactive sources between facilities.

\subsubsection{Shipping Containers}

The DOT is very specific on what containers can be used for the transportation of radioactive sources. The only containers allowed for shipping radioactive sources are prescribed in CFR 49. Authorized

\footnotetext{
${ }^{1}$ http://www.nrc.gov/reading-rm/doc-collections/cfr/part071/full-text.html
} 
containers are extensively tested and certified by the DOT to meet very rigorous accident scenarios and the individual package has pedigreed certification documentation that accompanies it wherever it travels. Also, each container requires at least one trained person to open, close, and seal it for shipment. Because the opening and closing of the container can only be performed by trained individuals, facilities that do not have trained staff will be required to arrange the services of staff from the shipping facility, or another facility in order to access materials within those containers. Recently, several types of shipping containers have lost their licensing for radioactive source transfer, which has resulted in fewer options for shipping sealed sources within the complex. ${ }^{2}$

\subsubsection{Personnel}

Training requirements for staff involved in radioactive source transfers are dictated by the specific isotope being shipped and the dose rate of that material. The actual cost of staff support is difficult to assess because variances in charge out rates between facilities, however facilities that maintain trained staff may already have support mechanisms in place. Most DOE sites should have the necessary staff to complete a shipment. However, if a site does not have the necessary personnel on-site, a trained staff member from another site must accompany the shipment to its destination. Travel and labor for shipper staff accompaniment must be considered for source shipments in which the shipping or receiving location does not have the required staff.

The quantity of material or the presence of specific isotope(s) may have additional influences on the number of trained personnel required to accompany a shipment. High dose rate and attractive material shipments represent situations requiring the maximum staffing requirements. The following types of staff may be required to ship or receive radioactive materials:

- Fission Material Handler (FMH)

- MBA custodian (applies tamper indicating device (TID))

- Shipper or receiver source custodian

- Radiation Protection Technician (RPT, to survey the shipment for contamination and dose rate confirmation)

- Teamsters (Physical transportation of the shipping package to/from shipping dock)

\subsection{Shipping of Radioactive Sources}

The shipment of radioactive sources is a process which fundamentally entails six specific steps: 1) verifying intended receiver licensing for possession of the material; 2) obtaining permissions for shipment/receipt of the material from both facilities' DOE site offices; 3) coordinating radioactive materials shipments with the local safeguards offices; 4) arranging shipping resources, containers, trained personnel, transportation etc.; 5) packaging of source materials; and 6) providing the appropriate documentation.

\footnotetext{
2 “DOE Certified Radioactive Materials Transportation Packaging." DOE/EM, 08 August 2008. http://rampac.energy.gov/docs/news/EM-PCP-certified-pkgs-8808.pdf, accessed 29 August 2013.
} 
PNNL-22810

\subsubsection{Step 1: Verifying Licensing}

The first step in making arrangements for the shipment of any nuclear or radiological material is assuring that the receiving party has the appropriate licenses in place to receive the type and quantity of material desired. 10 CFR.30.41 requires the shipper to possess a either a copy of the recipients license to possess the material(s) being shipped or a letter certifying the recipient has an appropriate license before material shipment can be arranged. The licensing documentation must contain the specific location's approval to receive the specified radioactive material.

\subsubsection{Step 2: Obtaining Local Permissions}

To ship or receive nuclear material at a DOE site, the local site office must be contacted and an official letter must be received granting permission to ship or receive the radioactive material. The letter should contain information on the source, including the isotope, weight, composition, and form.

\subsubsection{Step 3: Coordinating with the Safeguards Office}

Depending on the material, shipments may need to be coordinated with the local safeguards office. Coordination with safeguards is necessary for any accountable nuclear material. Accountability is based upon both material type and a designated threshold quantity. Materials and threshold quantities are dictated by the DOE, and the DOE accountable materials table can be found in DOE Order 474.2, Nuclear Material Control and Accountability. All DOE sites are required to account for the materials listed in Table 1. Any item containing greater than the threshold quantity of material is required to be safeguarded. For accounting purposes, each of the threshold quantities rounds up to the accounting unit. For example, enriched uranium is accounted for in whole grams, natural uranium in whole kilograms, and $\mathrm{Pu}-238$ to the tenth of a gram. 
PNNL-22810

\begin{tabular}{|l|l|}
\hline \multicolumn{1}{|c|}{ Material } & \multicolumn{1}{c|}{ Threshold Quantity } \\
\hline Americium-241 & 0.5 grams \\
\hline Americium-243 & 0.5 grams \\
\hline Berkelium & 0.5 micrograms \\
\hline Californium-252 & 0.5 micrograms \\
\hline Curium & 0.5 grams \\
\hline Depleted Uranium & 0.5 kilograms \\
\hline Deuterium & 0.05 kilograms \\
\hline Enriched Uranium & 0.5 grams \\
\hline Enriched Lithium & 0.5 kilograms \\
\hline Neptunium-237 & 0.5 grams \\
\hline Normal Uranium & 0.5 kilograms \\
\hline Plutonium-239-241 & 0.5 grams \\
\hline Plutonium-238 & 0.05 grams \\
\hline Plutonium-242 & 0.5 grams \\
\hline Thorium & 0.5 kilograms \\
\hline Tritium & 0.005 grams \\
\hline Uranium-233 & 0.5 grams \\
\hline
\end{tabular}

Table 1: DOE Accountable Materials

\subsubsection{Step 4: Making Shipping Arrangements}

In order to make arrangements for shipping nuclear or radiological materials, the type of shipment must first be determined. Guidelines for determining the shipment type can be found in DOT 173.435. The type of shipment will determine the container/shipping package that must be used. Certain shipping containers are in short supply within the DOE complex. If there is not an approved container, or if additional evaluation must be performed to amend the container's Certificate of Compliance (CoC), this step can end up being quite costly and time consuming.

The sources generally needed for safeguards technology development and calibration will require one of three different categories of shipping containers: Type A, Type B and specially designed casks. Type A containers are used for solid materials, and consist of a 5-10 gallon drum with custom-cut foam spacers to cushion and center the sources. Many DOE sites maintain a limited inventory of these drums. Multiple items can be combined into a single package as long as it doesn't exceed the Type A quantity limit. Type $\mathrm{B}$ (fissile material) containers are required for $\mathrm{Pu}-238$, reactor grade $\mathrm{Pu}$, weapons grade $\mathrm{Pu}$, and $\mathrm{Pu}-239$ $(>1 \mathrm{~g})$. These containers include the 9977 or ES-3100 drums. Many DOE sites also typically maintain a limited inventory of Type B containers. As with Type A containers, multiple items can be combined into a single drum as long as they don't exceed the package design limits. While the 9977 drums have several approved configurations, it is difficult to fit more than 2 or 3 sources in a 9977 drum.

Some shipments of radioactive or nuclear materials, for example Cm-244 and Cs-137, require a specially-designed shielded cask. Savannah River National Lab is the design authority on the package and can answer any specific technical questions regarding its design. The complex inventory of the drums is also limited because they are only produced in batches where they have a sufficient number to make fixed 
costs reasonable on a per container basis. There are additional upfront costs for a leak tester and associated tools, and leak testing equipment must be calibrated annually.

A finite number of shipping containers are in circulation throughout the complex. Also, limited production runs occur where a small number of packages are fabricated and paid for by parties requesting them. Radioactive materials shippers around the DOE complex have been found to be very cooperative and willing to help out by lending packages for a specific, well documented period of time.

Before any shipment can occur, the shipper is required to review the package $\mathrm{CoC}$ to determine if any testing or maintenance is required. The shipper may be required to check or change package seals and other components or perform leak testing. In addition, the shipper must take radiation measurements at specific locations on and around the package to make sure that the levels are below the required limits. The container must also be inspected to ensure it is physically undamaged. Dents and other general superficial damage are permissible only if they do not reduce the integrity of the container or obscure labels.

In addition, there are different requirements for "Agreement States," and "Non-Agreement States." Agreement States are those states that have agreed to accept direct responsibility for the transportation of radioactive materials within their borders, through an agreement with the Nuclear Regulatory Commission (37 Agreement States currently exist within the United States); whereas Non-Agreement States are those states who have not accepted the responsibility and therefore all radioactive materials transportation within their borders remain under the direct cognitive authority of the NRC. As a result, the ultimate destination and route of transit of the radioactive material must be evaluated before shipment, to ensure proper regulations have been met.

\subsubsection{Step 5: Packing Nuclear Materials}

Prior to packaging the material, it should be surveyed and recorded. Radiation surveys are also required after the material is placed within the shipping container. The survey must be conducted to find the maximum dose rate for the shipment and is used to mark the shipment. Surface contamination surveys must also be conducted to verify it is below the allowed limit. The contamination value is also the highest value found, rather than the average (see 173.403).

After the surveying has been performed and if the shipment meets the radiation requirements, then the container can be closed. The sealing must be performed by a trained professional, specifically trained to seal the exact container being used. There must be an equivalently trained person to open the container at its destination. After surveying and sealing has been completed and documented, the security seal can be installed. For Type A containers, each container must have a security seal and it must be installed by someone specifically trained in applying it. The seal must be tamper indicating and records must be maintained to verify the container has not been tampered with upon its arrival at the destination.

10 CFR172.310 prescribes the marking and labeling requirements for radioactive shipments. In addition to other requirements, the markings must be durable and visually prominent. The markings must contain the name of the receiver, the shipping address, and the appropriate radioactive markings. If the container also contains an over pack or, inner container, it too must be labeled according to the requirements in 172.300. The markings for radioactive shipments are specified in 10 CFR172.403. 
PNNL-22810

\subsubsection{Step 6: Providing Shipment Documentation}

Shipping documentation requirements can be found in 10 CFR172.200. The purpose of these documents is to provide the shipper with all of the safety and delivery information on the material intended for transport. Documentation must contain all of the information emergency responders would need to understand, if any safety issue were to arise involving the shipment. The documentation must also contain the name of the shipper/receiver and their addresses and contact information. Documentation of the contents is also required and should include activity, isotopics, class, UN number ${ }^{3}$, physical form, chemical form, and hazard category.

The shipper must also meet the Department of Transportation's requirements for shipment of the nuclear material including route selection, vehicle condition and placarding, driver training, package marking, labeling, and other shipping documentation.

Records of radioactive source shipments must be retained for three years.

\subsection{Other Considerations}

In addition to the above, careful consideration of the available shipment options should be made to ensure the timing of the shipment meets the required delivery date. Several qualified shippers offer "time critical" options that keep the shipment in transit to its destination - reducing the potential for a delayed arrival or a lost shipment. Radioactive sources shipped by standard ground services have the potential for delay because there are restrictions on combining sources with certain items, such as food items.

Along with the logistical steps involved, radioactive source transfer activities should include planning for the possibility of a delayed shipment (due to vehicle accident or other mishap), lost shipment, or a damaged source. The plan should identify each potential scenario, the steps needed to recover from the situation, and the staff to contact.

\footnotetext{
${ }^{3}$ See International Atomic Energy Agency, "Guide to transport package labels and markings." http://wwwns.iaea.org/tech-areas/emergency/iec/frg/ti1-transport.asp, accessed September 6, 2013.
} 
PNNL-22810

\subsection{Logistics for Equipment Transfer}

While the transfer of nuclear materials between DOE sites may be one option to reduce procurements costs for similar source needs, it is not the exclusive option. Researchers may also transport their equipment to sites that have the needed materials (either through collaborating laboratories, or safeguards technology testing centers). Such an option might also decrease the number of sources required to support safeguards technology development and calibration overall, by providing those sources only for specific locations, and encouraging use of the resources at those selected facilities. This section has a brief overview of the logistical considerations necessary for safeguards equipment transfers.

\subsection{Introduction to Equipment Transfers}

Non-routine movement of fragile solid-state radiation detector equipment between national laboratories can be a complex process. There are multiple regulations and no universal set of steps required for shipment between all locations. When planning the transfer of radiation detection equipment between facilities, the following issues must be considered: radiological contamination, facility approval, security, budget, and shipping considerations. In an effort to better understand the process necessary for detector equipment transport, guidelines have been developed for planning, designing, and transporting solid-state detectors (e.g., germanium, sodium iodide), based upon PNNL historic experiences. These guidelines may serve as a reference for other national laboratories when considering the transfer of detector equipment. There is not one universal process, as no two laboratories have the exact same requirements or procedures.

During the inception phase, both laboratories need to discuss the scope, project objectives and feasibility of the proposed project. A complete list of equipment (e.g.: detectors, computers, external hard drives), potential hazards (e.g.: cryogens, electronics, lead, radioactive sources) and special requirements should be provided to the receiving laboratory. Potential special requirements for offsite equipment transfer and care include:

- Heavy lifting equipment (e.g., forklift, hand cart)

- Laboratory space

- Power supply

- Environmental stability (e.g., temperature, humidity, vibration)

- Background radiation

- Electronics approval/examination

- Support staff

- Continuous maintenance (liquid nitrogen fills)

Potential hold-ups should be identified. For example, a substantial amount of time might be needed for equipment security checks at the receiving facility and additional security tags might be needed prior to entry.

\subsection{Equipment Packaging}

Prior to shipping equipment offsite, a radiological survey needs to be performed if equipment was previously in the presence of radiological material. Since detector equipment is fragile, it is typically 
packaged within the facility it is located. Laboratory teamsters and carpenters typically assist with packaging; however, the scientific staff will be present to assist due to the fragility and cost of the equipment. If the original detector packaging materials and crate are no longer available, similar materials can be purchased through the equipment manufacturer or one can be customized at the laboratory. The solid-state crystal should be separately packaged and secured inside of the shipping crate along with the rest of the detector equipment. If a sodium iodide solid-state crystal is to be transported, it should be packaged inside of an insulated box due to temperature fluctuation sensitivity (germanium solid-state crystals are not as sensitive to temperature fluctuation).

\subsection{Transportation}

The package will then typically be transported to the laboratory's onsite shipping and receiving warehouse. At the warehouse, the appropriate paperwork will be submitted for off-site shipping and the package will be handed over to the courier. Once the paperwork is completed, the remaining work put into transporting the package to the carrier is covered by the laboratory's overhead. Packages can also be shipped directly from the place of packaging to the receiving laboratory's warehouse if necessary.

A variety of courier services have previously been used by PNNL for the transport of detector equipment including FedEx Ground, FedEx Custom Critical, and LPL Transport. The selected mode of transport relates directly to the level of care the equipment requires during transportation and the timeliness of the delivery. These services can range in cost from $\$ 1,500$ to $\$ 6,500$ depending on the transport urgency (non-stop travel), transport distance and lead time given to the courier. For example, FedEx Custom Critical was given a lead-time of 4 weeks to transport a 4'x4'x4' crate containing two fragile solid-state detectors over 1,500 miles. The total time for the transport took 29 hours and cost $\$ 2,500$. Typical ground transport is estimated to be closer to $\$ 1,500$. Another caveat to consider when choosing a courier is in the laboratory's policies for on-site personnel approval (e.g., badging or clearance requirements, national origin). Some couriers, like FedEx Custom Critical, employee drivers with DOE clearances.

\subsection{Other Considerations}

Other things to consider when planning equipment transfers include laboratory work schedule (i.e. work days, extended hours), data monitoring/collection needs, use of radioactive calibration sources, high-security facilities requirements, and ultra-clean requirements (if needed).

When considering data monitoring and collection needs, remote access to equipment is preferential, especially when data collection is over an extended period of time without the need of staff oversight. However, it should be noted security requirements at some facilities may preclude or restrict the use of electronic transmitting devices, or internet access of equipment. There may also be restriction associated with accessing of equipment remotely, depending upon the equipment, its function, and the site of deployment. Radioactive calibration sources are another necessary component for effective data collection. Typically, the laboratory that owns the detector equipment provides the necessary calibration sources, because it is that facility that must accept the responsibility for management of the source materials. For that reason, the cost of radioactive calibration preparation and movement are not reflected in this report. High-security facilities will also require more preparation, documentation and resources for 
PNNL-22810

incoming shipments, and last, ultra-clean rooms may have more strict requirements and protocols, which will also result in increased cost.

Page 12 
PNNL-22810

\subsection{Repackaging of PNNL Pu Sources}

The Source Suitability Questionnaire report identified two plutonium oxide powder sources at PNNL that could be used to fulfill PNNL source requests if repackaged and recertified. This section will outline the requirements for that work to be completed.

The current plutonium oxide sources are in old (1970's) era containers. These containers have been analyzed to meet special form source requirements using the information that was available from the fabrication in the 1970's. The sources are self-certified special form sources that are acceptable for use at PNNL, but certification does not necessarily meet requirements from other sites. These sources need to be repackaged into a package that is special form that meets current process control standards. The revised package would have be a DOT reviewed package with an "IAEA Certificate of Competent Authority Special Form Radioactive Materials Certificate." This certificate is widely accepted both national and internationally, as assurance that the material is in an approved special form package.

The remainder of Section 5.0 has been adapted from a 2010 PNNL white paper prepared for the Defense Nuclear Detection Office (DNDO), "Reactor Grade Plutonium Oxide Sealed Source Specification and Program Plan."

\subsection{Introduction}

This section describes the process to fabricate plutonium oxide disks and assemble a sealed source using an existing container design, from plutonium oxide powder currently in-use at PNNL.

\subsection{Nitric Acid Dissolution and Am Removal}

The Pu feedstock will first be dissolved in nitric acid as a precursor to americium removal and cleanup of the plutonium. The solution will then be passed through an existing counter-current solvent extraction system (PNNL's Radiochemical Processing Laboratory (RPL) lab 506) made up of a series of $2 \mathrm{~cm}$ centrifugal contactors where the plutonium will be separated from the americium. As a secondary method, an ion exchange column can be installed and used to separate plutonium from americium. Both techniques are well established technology that results in a plutonium nitrate solution that has had americium and chemical impurities removed.

\subsection{Pu Precipitation and Calcining}

After nitric acid dissolution and Am removal, the Pu will be precipitated from the nitric acid solution with oxalic acid as the hexahydrate $\mathrm{Pu}(\mathrm{C} 2 \mathrm{O} 4) 2 \cdot 6 \mathrm{H} 2 \mathrm{O}$. The concentration of $\mathrm{Pu}$ should be between 7 to $24 \mathrm{~g} /$ liter. The oxalate is then heated in an air atmosphere furnace at up to $600-800^{\circ} \mathrm{C}$ to produce the plutonium oxide. The optimal heating temperature is $750^{\circ} \mathrm{C}$. PNNL's RPL lab 515 has a glovebox well equipped to perform the oxide preparation.

\footnotetext{
${ }^{4}$ CL Painter, SA Jones, AW Prichard, BK McNamara, DL Daldwin, and RT Pagh. January 2010. PNNL-SA-70505
} 
PNNL-22810

\subsection{Powder Conditioning and Pressing}

The powder is conditioned using a $10 \%$ water solution of polyvinyl alcohol with 7 mass $\%$ of zinc stearate powder added to a $15-20 \mathrm{~g}$ batch of the $\mathrm{Pu}$ oxide powder. The mixture is mixed in a vortex mixer and then dried in air for 10-12 h. The powder is compressed into cakes and the cakes are then broken up; a fraction of granules ranging in diameter from 0.2 to $0.8 \mathrm{~mm}$ is separated out. The granular material is then re-mixed with zinc stearate (0.1-0.2 mass\%) and compressed into a "green" pellet.

\subsection{Sintering}

After the plutonium oxide is pressed into the desired shape, it is heated to cause the pressed plutonium oxide to bond together through a process called sintering. One or more pellets would be sintered to create a high density finished ceramic shape, with three possible approaches as described below. The sintering process requires the pellet to be heat-treated in air prior to sintering using the following regime: $100^{\circ} \mathrm{C}-1 \mathrm{~h}, 200^{\circ} \mathrm{C}-0.5 \mathrm{~h}, 300^{\circ} \mathrm{C}-0.5 \mathrm{~h}, 500^{\circ} \mathrm{C}-1 \mathrm{~h}$. The pellet is then sintered to a temperature as high as $1750^{\circ} \mathrm{C}$, though lower temperatures have been used for differing target density, in an argon-hydrogen atmosphere (with $\mathrm{H}_{2}$ content of 5-7 vol.\%) or in a vacuum. Existing RPL sintering furnace capability currently allows about $1600^{\circ} \mathrm{C}$ maximum temperature, limiting target densities to about $8 \mathrm{~g} / \mathrm{cm} 3$. New sintering furnace equipment would need to be acquired for the higher temperatures and resulting higher densities. The geometrical density of the pellets can be determined using a blade micrometer or equivalent gauge and the pellet weight.

The process parameters associated with pressing and sintering would need to be fully developed such that the final puck dimensions are predicable. The green pellet may shrink on the order of twenty percent. Several iterations will be needed to define these process parameters.

\subsection{Final Sealed Source Assembly}

The additional work required to support the effort is to build additional parts for the next sealed source, revise the existing assembly procedure to discuss safety issues associated with the oxide and undergo another internal safety and readiness review. 
PNNL-22810

\subsection{Conclusions}

This report documents the logistical considerations for transferring both nuclear sources, and safeguards equipment between DOE sites. Laboratory-level guidelines related to shipment of sources or equipment tend to be high-level and without detailed instructions due to the variable requirements for different types of shipments. Nor is there a clear consensus regarding the costs of such shipments, as shipment cost has varied widely based on the materials being shipped, and the level of experience of the shipping party.

Due to the commonalities of source requests across the DOE complex, as identified in the Reconciled Gap Analysis report [2], there appear to be several options that DOE may consider implementing to respond to source needs that cannot be met through facility transfers. The first option may be a source sharing mechanism. This option may ultimately be less expensive and less logistically complicated than the procurement and distribution of multiple individual sources to fulfill each lab source request. A second option may be the establishment of regionally accessible testing locations, which could be stocked with a limited supply of highly desirable sources, and could provide the facilities and resources to support testing and calibration needs of multiple laboratories. These two mechanisms would require researchers at DOE laboratories to either: (a) ship sources between DOE sites for safeguards technology development, or (b) ship their safeguards equipment to centralized testing locations that hold a collection of sources. While there are advantages and disadvantages to both options, a detailed cost-benefit analysis should be conducted to deliver a more comprehensive comparison. 
PNNL-22810

\subsection{References}

[1] Orton, CR and ZN Gastelum, Gap Analysis of Department of Energy Radiological Sealed Sources, Standards, and Materials for Safeguards Technology Development, July 2012. PNNL-21529.

[2] Gastelum, ZN and LL Duckworth, Reconciliation of Source Needs and Surpluses across the U.S. Department of Energy National Laboratory Complex. PNNL-22143, January 2013.

[3] Gastelum, ZN and LL Duckworth, Final Results of the DOE Complex Radiological/Nuclear Source Suitability Questionnaire, September 2013. PNNL-22714.

[4] Gastelum, ZN, LL Duckworth, and TR Hay, Final Report on the Commercial and Government Vendor Availability of Requested Sources without In-Complex Available Matches, September 2013. PNNL-22713. 